Proceedings

\title{
Introducing chiral N-BODIPYs: Promising dyes for chiroptical applications
}

\author{
César Ray, Florencio Moreno, Antonia R. Agarrabeitia, María J. Ortiz, Beatriz L. Maroto* and Santiago de la \\ Moya* \\ Departamento de Química Orgánica I. Facultad de Ciencias Químicas. Universidad Complutense de Madrid. Ciudad \\ Universitaria s/n, 28040 Madrid, Spain. \\ * Correspondence: belora@ucm.es, santmoya@ucm.es; Tel.: +34-913945155, +34-913945090 \\ + Presented at The 21st International Electronic Conference on Synthetic Organic Chemistry. 1-30 November 2017.
}

Academic Editor: name

Received: date; Accepted: date; Published: date

\begin{abstract}
N-BODIPYs (diaminoborondipyrromethenes) were recently described by us for the first time as a new family of BODIPY dyes with huge technological potential. We present now a series of unprecedented chiral $\mathrm{N}$-BODIPYs, which have been straightforwardly synthesized in a simple one-pot procedure starting from parent F-BODIPYs and chiral sulfonamides. The circular dichroism (CD) of the new chiral dyes has been measured with the aim of studying the possibility of modulating the CD signal in chiral BODIPYs by simple chemical functionalization.
\end{abstract}

Keywords: Organic Dyes, BODIPYs, Chiroptics, Circular dichroism.

\section{Introduction}

BODIPYs (boron dipyrromethenes; 4-bora-3a,4a-diaza-s-indacenes) constitute one of the most valuable families of technological dyes [1-10]. Nowadays, there is a plethora of available synthetic procedures for their direct functionalization, focused on appropriate modulation of key physical (mainly photophysical) properties. This ample reactivity allows the derivatization of BODIPYs at their dipyrrin moiety with a great variety of pendant functional groups (blue in Figure 1) [3,8,11-20]. However, less synthetic diversity is found when directly functionalizing BODIPYs at boron (red in Figure 1) [21-36]. This boron functionalization, virtually restricted to $O$ - and C-BODIPYs until recently, has allowed the facile preparation of dyes with enhanced photostability for lasing [21-24], with improved water solubility for biological applications [25-27], with boosted energy-transfer processes for efficient light collection [19,28-32] or with enhanced chiral perturbation enabling circularly polarized luminescence (CPL) [33-36], among other valuable properties.

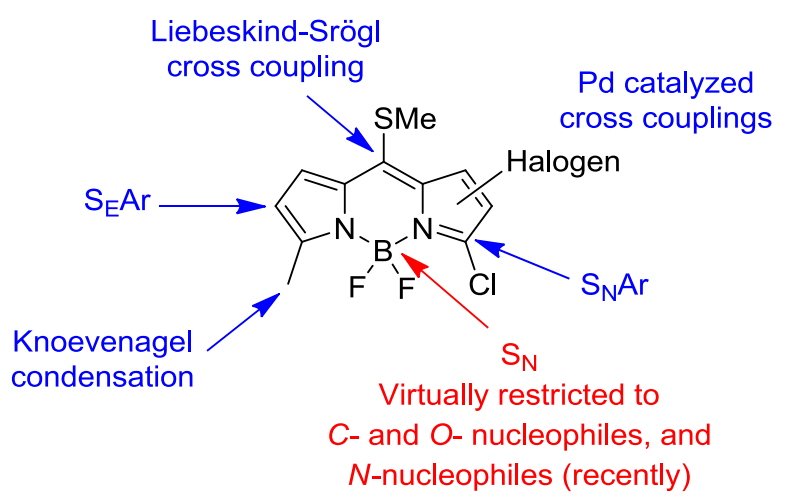

Figure 1. Some useful chemical transformations in BODIPYs. 
Recently, de la Moya group has reported a protocol to directly functionalize BODIPYs at boron with two nitrogen moieties thus obtaining the first N-BODIPYs (e.g. 1, Figure 2) [37]. Nitrogens with electron withdrawing groups (alkyl- or arylsulfonyl) and electron rich dipyrrins (peralkylated) were used to stabilize the corresponding diaminoboron-dipyrrin complex. This combination gave place to highly stable N-BODIPYs, which additionally turned out to be highly fluorescent [37].
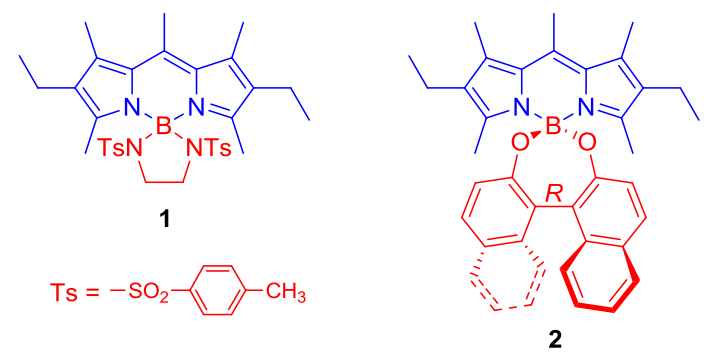

Figure 2. First N-BODIPY (1) and spiranic chiral O-BODIPY (2) enabling CPL described by de la Moya.

The new N-BODIPYs show great versatility for chemically functionalizing BODIPYs. Thus, the distinct key bonding features of nitrogen compared with those of oxygen (enhanced bond valence and different bond directionality) should open up new possibilities for functionalizing BODIPY dyes, allowing an increase in the number of pendant moieties near the BODIPY chromophore (from two in O-BODIPYs, up to four different residues in N-BODIPYs) [37]. Such versatile and multiple functionalization is of great interest for achieving a smarter modulation of the BODIPY photophysics, which should increase the applicability of these dyes as advanced photonic platforms, for example in chiroptical applications, a field that has experienced an exponential growth in the last years. Thus, circular dichroism (CD) or circularly polarized luminescence (CPL) have found application in the improvement and potential development of multiple photonic tools as display devices including 3D optical displays, optical storage and processing systems, spintronics-based devices, biological probes and signatures, security tags, CPL lasers and enantioselective CPL sensors, among others [38-46]. In this chiroptical context, our group described a new simple structural design for developing small organic molecules (SOM) enabling CD and CPL from inherently achiral chromophores [33]. This strategy is based on a spiranic O-BODIPY, which is chirally perturbed by a 1,1'-binaphtyl unit orthogonally tethered to it in a spiranic fashion, providing CPL levels $\left(\left|g_{\text {lum }}\right|\right)[47]$ in solution falling into the usual range $\left(10^{-5}\right.$ to $\left.10^{-2}\right)$ of that obtained from other SOMs (2, Figure 2).

On the basis of the said new design for CPL-SOMs based on BODIPY, exemplified by 2, and taking advantage of the easiness of preparation and high stability, fluorescence and chemical versatility of the newly discovered N-BODIPYs [37], we decided to prepare a battery of chiral N-BODIPYs and carry out a study on the variation of their chiroptical properties with the structural factors. In this preliminary study, the synthesis and measurement of $\mathrm{CD}$ is accomplished.

\section{Results and discussion}

Three different modulation strategies will be followed to study the influence of the structure on the chiroptical properties of chiral N-BODIPYs: (1) the generation of a chiral center at the boron atom itself, (2) the use of a diamine moiety with stereogenic carbons attached to the nitrogens and (3) the use of a sulfonamide moiety with a conformationally-mobile pending chiral fragment. Additionally, the designed structures will present either $C_{1}$ or $C_{2}$ symmetry. These variations will make possible to carry out a preliminary study on the effect of different factors (distance of the stereogenic elements to the chromophore, molecular symmetry, conformational flexibility of stereogenic moieties, etc.) on the CD properties of chiral N-BODIPYs.

The selected library of easily accessible chiral N-BODIPYs shown in Figure 3 was chosen to comprise the above mentioned structural factors. Thus, for example, $\mathbf{3 a - c}$ are $C_{2}$-symmetric structures, which, in principle, is a good structural motif to achieve CD [48]. In 3c the chirality has been introduced in the sulfonamide moiety, whereas in $\mathbf{3} \mathbf{a}$ and $\mathbf{b}$, the chiral center is attached to the nitrogen and thus closer to the central boron atom. On the other hand, an asymmetric dipyrrin has been selected to see the influence of a stereogenic boron atom (diastereomeric couple $\mathbf{4 d}$ ). 


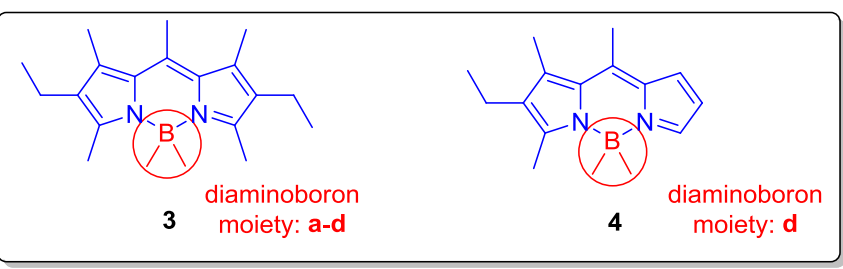

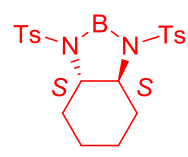

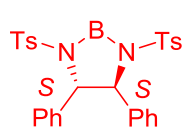

b

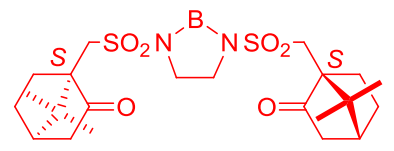

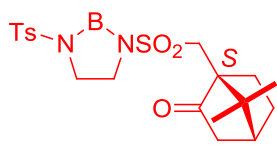

Figure 2. Developed library of chiral N-BODIPYs. Ts = p-toluenesulfonyl (tosyl).

The selected chiral N-BODIPYs were straightforwardly prepared using the procedure described by de la Moya [37] (Scheme 1), starting from the corresponding parent F-BODIPY and a chiral disulfonamide. The reaction of formation of the N-BODIPY is a simple one-pot nucleophilic substitution of fluorine by nitrogen promoted by boron trichloride (Scheme 1).
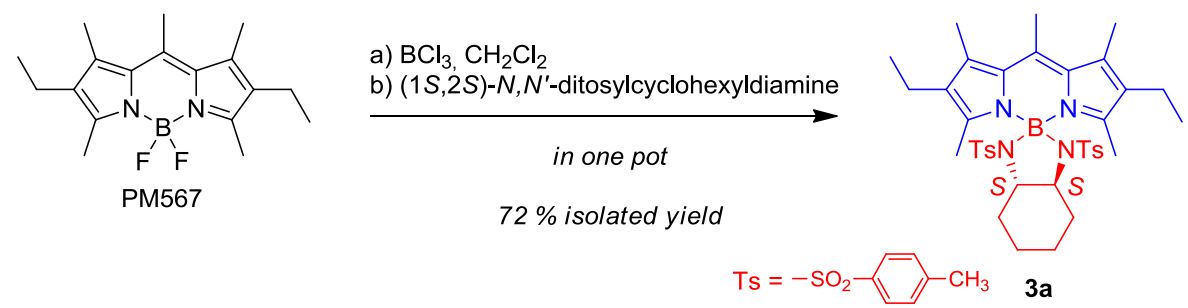

Scheme 1. Synthesis of chiral N-BODIPYs, exemplified for 3a.

On the one hand, $C_{2}$-symmetric N-BODIPYs 3a-c were made from a symmetric F-BODIPY (commercially available 2,6-diethyl-1,3,5,7,8-pentamethyl-F-BODIPY, PM567, Figure 4) and a symmetric chiral disulfonamide. These sulfonamides were in turn made either by reacting a chiral diamine $((1 S, 2 S)$-cyclohexane-1,2-diamine for a or $(1 S, 2 S)$-1,2-diphenylethane-1,2-diamine for $\mathbf{b}$ ) with $p$-toluenesulfonyl chloride, or achiral ethane-1,2-diamine with (1S)-camphorsulfonyl chloride, for c.

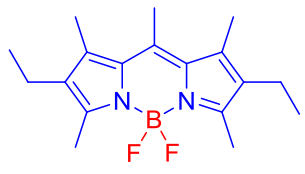

PM567

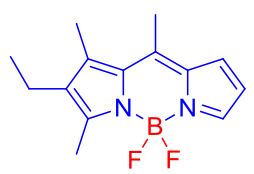

5

Figure 4. Starting F-BODIPYs.

On the other hand, $C_{1}$-symmetric $N$-BODIPYs $\mathbf{3 d}$ and $\mathbf{4} \mathbf{d}$ were made using either an asymmetric F-BODIPY or an asymmetric disulfonamide or both. As starting asymmetric F-BODIPY, easily accessible 2-ethyl-1,3,8-trimethyl-F-BODIPY [49] (5, Figure 4) was used. For the asymmetric disulfonamide (6d, Scheme 2), ethane-1,2-diamine was reacted in two steps, first with one equivalent of $p$-toluenesulfonyl chloride and then with one equivalent of (1S)-camphorsulfonyl chloride, giving place to $6 \mathbf{d}$ in $85 \%$ yield.

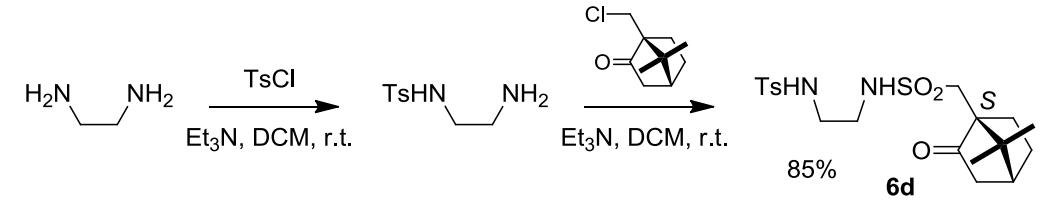

Scheme 2. Synthesis of asymmetric disulfonamide $\mathbf{6 d}$. 
The CD spectra of the obtained chiral N-BODIPYs were recorded in diluted chloroform solution and the corresponding $g_{a b s}[50]$ calculated. Except for 3c, all synthesized chiral N-BODIPYs were CD-active (see Table 1). Also noteworthy is the high fluorescence of all species, something of a great interest, as it is critical to the development of CPL-SOMs. However, no clear conclusions on the relationship between the dye structure and the $\mathrm{CD}$ properties can be extracted from this preliminary series.

Table 1. Kuhn's disymmetry ratio $\left(g_{a b s}\right)$ for studied $N$-BODIPYs (10-6 $\mathrm{M} \mathrm{CHCl}_{3}$ solution).

\begin{tabular}{c|c}
\hline $\boldsymbol{N}$-BODIPY & $\mathbf{1 0}^{\mathbf{3}} \cdot \mathbf{g}_{\text {abs }}$ \\
\hline 3a & $+0,53$ \\
3b & $+0,13$ \\
3c & 0 \\
3d & $-0,08$ \\
$\mathbf{4 d}$ & $+1,40$ \\
$\mathbf{4 d}$ & $-0,15$ \\
\hline
\end{tabular}

Thus, $\mathbf{3 a}$ and $\mathbf{3} \mathbf{b}$, both coming from chiral diamines with $\alpha$-stereogenic carbons, are CD-active, demonstrating that using easily-available chiral diamines is a good strategy for achieving CD in N-BODIPYs. However, the $g_{\text {abs }}$ values reached by them are significantly different (Table 1), which could be due to key differential conformational and/or steric factors.

From the $\mathrm{CD}$ results for camphor-derived $3 \mathbf{c}$ and $\mathbf{3 d}$, it seems that introducing this chiral element in the sulfonamide moiety is not a good strategy for achieving CD. Neither when the resulting structure has $C_{1}$-symmetry, nor when it has $C_{2}$-symmetry. However, the camphor moiety does clearly have an influence on the $\mathrm{CD}$ of the dye, since diastereomeric $\mathbf{4} \mathbf{d}$ and $\mathbf{4} \mathbf{d}$ ' show very different values of $g_{a b s}$ (Table 1 ).

At first, the highest value of $g$ abs for $\mathbf{4 d}(+1.40)$ seems to indicate that asymmetric boron is the best structural motif for a CD-active N-BODIPY. However, as above-mentioned, there has to be another effect playing, since both diastereomers show completely different $g_{a b s}$ values.

\section{Conclusion}

A series of unprecedented chiral N-BODIPYs have been straightforwardly synthesized. The measurement of the $\mathrm{CD}$ signalization of these new dyes shows that they can be $\mathrm{CD}$-active, exhibiting gabs values in the typical range of most of the CD-active dyes based on SOM. The interest of this chiroptical property (e.g., in high-resolution and chiral sensing), joined to excellent absorption/emission signatures and synthetic accessibility, make chiral N-BODIPYs to be potentially interesting for Chiroptics. Nonetheless, further investigation related with assessing the influence of the N-BODIPY structure in the dichroic signalization (level and sign) is needed to make possible the rational design of future chiral N-BODIPYs with improved properties for chiroptics. Is this line, research is being conducted by synthesizing and chiroptically studying (CD and CPL) new series of chiral N-BODIPYs.

Acknowledgments: Financial support from Spanish MICINN (MAT2014-51937-C3-2-P).

Author Contributions: S.M. conceived the work; S.M and B.L.M. designed the general experiments and supervised the overall work; C.R. performed the synthetic development of the dye series; F.M. designed the CD experiments; F.M., A.R.A. and M.J.O carried out the CD measurements and analyzed the data; B.L.M., S.M. and C.R. wrote the paper.

Conflicts of Interest: The authors declare no conflict of interest.

\section{References}

1. Costela, A.; García-Moreno, I.; Sastre, R. Polymeric solid-state dye lasers: Recent developments. Phys. Chem. Chem. Phys. 2003, 5, 4745-4763. DOI: 10.1039/B307700B.

2. Benniston, A. C.; Copley, G. Lighting the way ahead with boron dipyrromethene (BODIPY) dyes. Phys. Chem. Chem. Phys. 2009, 11, 4124-4131. DOI: 10.1039/B901383K.

3. Benstead, M.; Mehl, G. H.; Boyle, R. W. Functionalization of 3,5,8-Trichlorinated BODIPY Dyes. Tetrahedron 2011, 67, 3573-3601. DOI: 10.1021/JO501969Z. 
4. Boens, N.; Leen, V.; Dehaen, W. Fluorescent indicators based on BODIPY. Chem. Soc. Rev. 2012, 41, 1130-1172. DOI: 10.1039/C1CS15132K.

5. Kamkaew, A.; Lim, S. H.; Lee, H. B.; Kiew, L. V.; Chung, L. Y.; Burgess, K. BODIPY dyes in photodynamic therapy. Chem. Soc. Rev. 2013, 42, 77-88. DOI: 10.1039/C2CS35216H.

6. Fan, J.; Hu, M.; Zhan, P.; Peng, X. A new fluorescent probe for colorimetric and ratiometric detection of sulfur dioxide derivatives in liver cancer cells. Chem. Soc. Rev. 2013, 42, 29-43. DOI: 10.1038/SREP45294.

7. Singh, S. P.; Gayathri, T. Evolution of BODIPY Dyes as Potential Sensitizers for Dye-Sensitized Solar Cells. Eur. J. Org. Chem. 2014, 4689-4707. DOI: 10.1002/EJOC.201400093.

8. Ni, Y.; Wu, J. Far-red and near infrared BODIPY dyes: synthesis and applications for fluorescent pH probes and bio-imaging. Org. Biomol. Chem. 2014, 12, 3774-3791. DOI: 10.1039/C3OB42554A.

9. Kowada, T.; Maeda, H.; Kikuchi, K. BODIPY-based probes for the fluorescence imaging of biomolecules in living cells. Chem. Soc. Rev. 2015, 44, 4953-4972. DOI: 10.1039/C5CS00030K.

10. Bañuelos, J. BODIPY Dye, the Most Versatile Fluorophore Ever? Chem. Rec. 2016, 16, 335-348. DOI: 10.1002/TCR.201500238.

11. Bessette, A.; Hanan, G. S. Design, synthesis and photophysical studies of dipyrromethene-based materials: insights into their applications in organic photovoltaic devices. Chem. Soc. Rev. 2014, 43, 3342-3405. DOI: 10.1039/C3CS60411J.

12. Lu, H.; Mack, Y. Yang, J.; Shen, Z. Structural modification strategies for the rational design of red/NIR region BODIPYs. Chem. Soc. Rev. 2014, 43, 4778-4823. DOI: 10.1039/C4CS00030G.

13. Zhao, J.; Xu, K.; Yang, W.; Wang, Z.; Zhong, F. The triplet excited state of BODIPY: formation, modulation and application. Chem. Soc. Rev. 2015, 44, 8904-8939. DOI: 10.1039/C5CS00364D.

14. Ray, C.; Sánchez-Carnerero, E. M.; Moreno, F.; Maroto, B. L.; Agarrabeitia, A. R.; Ortiz, M. J.; López-Arbeloa, Í.; Bañuelos, J.; Cohovi, K. D.; Lunkley, J. L.; Muller, G.; de la Moya, S. Bis(haloBODIPYs) with Labile Helicity: Valuable Simple Organic Molecules That Enable Circularly Polarized Luminescence. Chem. Eur. J. 2016. 22, 8805-8808. DOI: 10.1002/chem.201601463.

15. Ray, C.; Bañuelos, J.; Arbeloa, T.; Maroto, B. L.; Moreno, F.; Agarrabeitia, A. R.; Ortiz, M. J.; López-Arbeloa, Í.; de la Moya, S. Push-pull flexibly-bridged bis(haloBODIPYs): solvent and spacer switchable red emission. Dalton Trans. 2016, 45, 11839-11848. DOI: 10.1039/C6DT01849A.

16. López Arbeloa, F.; Bañuelos, J.; Martínez, V.; Arbeloa, T.; López Arbeloa, Í. Structural, photophysical and lasing properties of pyrromethene dyes. Int. Rev. Phys. Chem. 2005, 24, 339-374. DOI: 10.1080/01442350500270551.

17. Loudet, A.; Burgess, K. BODIPY Dyes and Their Derivatives: Syntheses and Spectroscopic Properties. Chem. Rev. 2007, 107, 4891-4932. DOI: 10.1021/CR078381N.

18. Ziessel, R.; Ulrich, G.; Harriman, A. The chemistry of Bodipy: A new El Dorado for fluorescence tools. New. J. Chem. 2007, 31, 496-501. DOI: 10.1039/B617972J.

19. Ulrich, G.; Ziessel, R.; Harriman, A. The Chemistry of Fluorescent Bodipy Dyes: Versatility Unsurpassed. Angew. Chem. Int. Ed. 2008, 47, 1184-1201. DOI: 10.1002/ANIE.200702070

20. Boens, N.; Verbelen, B.; Dehaen, W. Postfunctionalization of the BODIPY Core: Synthesis and Spectroscopy. Eur. J. Org. Chem. 2015, 6577-6595. DOI: 10.1002/EJOC.201590085.

21. Jagtap, K. K.; Shivran, N.; Mula, S.; Naik, D. B.; Sarkar, S. K.; Mukherjee, T.; Maity, D. K.; Ray, A. K. Change of Boron Substitution Improves the Lasing Performance of Bodipy Dyes: A Mechanistic Rationalisation. Chem. Eur. J. 2013, 19, 702-708. DOI: 10.1002/CHEM.201202699.

22. Durán-Sampedro, G.; Agarrabeitia, A. R.; Cerdán, L.; Pérez-Ojeda, M. E.; Costela, A.; García-Moreno, I.; Esnal, I.; Bañuelos, J.; López-Arbeloa, Í.; Ortiz, M. J. Carboxylates versus Fluorines: Boosting the Emission Properties of Commercial BODIPYs in Liquid and Solid Media. Adv. Funct. Mat. 2013, 23, 4195-4205. DOI: 10.1002/ADFM.201300198.

23. Durán-Sampedro, G.; Esnal, I.; Agarrabeitia, A. R.; Bañuelos, J.; Cerdán, L.; García-Moreno, I.; Costela, A.; López-Arbeloa, Í.; Ortiz, M. J. First Highly Efficient and Photostable $\mathrm{E}$ and C-Derivatives of 4,4-Difluoro-4-bora-3a,4a-diaza-s-indacene (BODIPY) as Dye Lasers in the Liquid Phase, Thin Films, and Solid-State Rods. Chem. Eur. J. 2014, 20, 2646-2653. DOI: 10.1002/CHEM.201303579.

24. Manzano, H.; Esnal, I.; Marques-Matesanz, T.; Bañuelos, J.; López-Arbeloa, Í.; Ortiz, M. J.; Cerdán, L.; Costela, A.; García-Moreno, I.; Chiara, J. L. Unprecedented J-Aggregated Dyes in Pure Organic Solvents. Adv. Funct. Mat. 2016, 26, 2756-2769. DOI: 10.1002/ADFM.201505051.

25. Fan, G.; Yang, L.; Chen, Z. Water-soluble BODIPY and aza-BODIPY dyes: synthetic progress and applications. Front. Chem. Sci. Eng. 2014, 8, 405-417. DOI: 10.1007/S11705-014-1445-7

26. Poirel, A.; Retailleau, P.; De Nicola, A.; Ziessel, R. Oxidative Coupling of 1,7,8-Unsubstituted BODIPYs: Synthesis and Electrochemical and Spectroscopic Properties. Chem. Eur. J. 2014, 20, 1252-1257. DOI: 10.1021/JO301300B. 
27. Yang, L.; Fan, G.; Ren, X.; Zhao, L.; Wang, J.; Chen, Z. Aqueous self-assembly of a charged BODIPY amphiphile via nucleation-growth mechanism. Phys. Chem. Chem. Phys. 2015, 17, 9167-9172. DOI: 10.1039/C5CP00207A.

28. Ziessel, R.; Ulrich, G.; Haefele, A.; Harriman, A. An Artificial Light-Harvesting Array Constructed from Multiple Bodipy Dyes. J. Am. Chem. Soc. 2013, 135, 11330-11344. DOI: 10.1021/JA4049306.

29. Sánchez-Carnerero, E. M.; Gartzia-Rivero, L.; Moreno, F.; Maroto, B. L.; Agarrabeitia, A. R.; Ortiz, M. J.; Bañuelos, J.; López-Arbeloa, Í.; de la Moya, S. Spiranic BODIPYs: a ground-breaking design to improve the energy transfer in molecular cassettes. Chem. Commun. 2014, 50, 12765-12767. DOI: 10.1039/C4CC05709K.

30. Bandi, V.; Das, S. K.; Awuah, S. G.; You, Y.; D'Souza, F.; Thieno-Pyrrole-Fused 4,4-Difluoro-4-bora-3a,4a-diazas-indacene-Fullerene Dyads: Utilization of Near-Infrared Sensitizers for Ultrafast Charge Separation in Donor-Acceptor Systems. J. Am. Chem. Soc. 2014, 136, 7571-7574. DOI: 10.1021/JA503015F.

31. Esnal, I.; Durán-Sampedro, G.; Agarrabeitia, A. R.; Bañuelos, J.; García-Moreno, I.; Macías, M. A.; Peña-Cabrera, E.; López-Arbeloa, Í.; de la Moya, S.; Ortiz, M. J. Coumarin-BODIPY hybrids by heteroatom linkage: versatile, tunable and photostable dye lasers for UV irradiation. Chem. Chem. Phys. 2015, 17, 8239-8247. DOI: 10.1039/C5CP00193E.

32. Zhang, S.; Wang, Y.; Meng, F.; Dai, C.; Cheng, Y.; Zhu, C. Circularly polarized luminescence of AIE-active chiral O-BODIPYs induced via intramolecular energy transfer. Chem. Commun. 2015, 51, 9014-9017. DOI: 10.1039/C5CC01994J.

33. Sánchez-Carnerero, E. M.; Moreno, F.; Maroto, B. L.; Agarrabeitia, A. R.; Ortiz, M. J.; Vo, B. G.; Muller, G.; de la Moya, S. Circularly Polarized Luminescence by Visible-Light Absorption in a Chiral O-BODIPY Dye: Unprecedented Design of CPL Organic Molecules from Achiral Chromophores. J. Am. Chem. Soc. 2014, 136, 3346-3349. DOI: 10.1021/JA412294S.

34. Alnoman, R. B.; Rihn, S.; O'Connor, D. C.; Black, F. A.; Costello, B.; Waddell, P. G.; Clegg, W.; Peacock, R. D.; Herrebout, W.; Knight, J. G.; Hall, M. J. Circularly Polarized Luminescence from Helically Chiral N,N,O,O-Boron-Chelated Dipyrromethenes. Chem. Eur. J. 2016, 22, 93-96. DOI: 10.1002/CHEM.201504484.

35. Lu, H.; Mack, J.; Nyokong, T.; Kobayashi, N.; Shen, Z. Optically active BODIPYs. Coord. Chem. Rev. $2016,318,1-15$. DOI: 10.1016/J.CCR.2016.03.015.

36. Jiménez, J.; Cerdán, L.; Moreno, F.; Maroto, B. L; García-Moreno, I.; Lunkley, J. L.; Muller, G.; de la Moya, S. Chiral Organic Dyes Endowed with Circularly Polarized Laser Emission. J. Phys. Chem. C, 2017, 121, 5287-5292.

DOI: 10.1021/ACS.JPCC.7b00654.

37. Ray, C.; Díaz-Casado, L.; Avellanal-Zaballa, E.; Cerdán, L.; García-Moreno, I.; Bañuelos, J.; Maroto, B. L.; Moreno, F.; López-Arbeloa, Í.; de la Moya, S. N-BODIPYs Come into Play: Smart Dyes for Photonic Materials. Chem. Eur. J. 2017, 23, 9383-9390. DOI: 10.1002/CHEM.201701350.

38. Canary, J. W.; Dai, Z.; Mortezaci, S. Spectroscopic Analysis: Chiropctical Sensors, in Comprehensive Chirality, ed. Carreira, E. M. and Yamamoto, H.; Elsevier, Amsterdam, 2012, Vol 8, pp. 600-624.

39. Zsila, F. Electronic Circular Dichroism Spectroscopy in Pharmaceutical Sciences Encyclopedia, 2010, Vol 7, pp.1-61.

40. Berova, N.; Di Bari, L.; Pescitelli, G. Application of electronic circular dichroism in configurational and conformational analysis of organic compounds. Chem. Soc. Rev. 2007, 36, 914-931. DOI: 10.1039/B515476F.

41. Wagenknecht, C.; Li, C.-M.; Reingruber, A.; Bao, X.-H.; Goebel, A.; Chen, Y.-A.; Zhang, Q.; Chen, K.; Pan, J.-W. Experimental demonstration of a heralded entanglement source. Nat. Photonics 2010, 4, 549-552. DOI: 10.1038/NPHOTON.2010.123.

42. Sherson, J. F.; Krauter, H.; Olsson, R. K.; Julsgaard, B.; Hammerer, K.; Cirac, I.; Polzik, E. S. Quantum teleportation between light and matter. Nature 2006, 443, 557-560. DOI: 10.1038/NATURE05136.

43. Carr, R.; Evans, N. H.; Parker, D. Lanthanide complexes as chiral probes exploiting circularly polarized luminescence. Chem. Soc. Rev. 2012, 41, 7673-7686. DOI: 10.1039/C2CS35242G.

44. Muller, G. Luminescent chiral lanthanide(III) complexes as potential molecular probes. Dalton Trans. $2009,9692-9707$. DOI: 10.1039/B909430J.

45. Sánchez-Carnerero, E. M.; Agarrabeitia, A. R.; Moreno, F.; Maroto, B. L.; Muller, G.; Ortiz, M. J.; de la Moya, S., Circularly Polarized Luminescence from Simple Organic Molecules. Chem. Eur. J. 2015, 21, 13488-13500. DOI: 10.1002/CHEM.201501178.

46. Cave, R. J. Chemistry. Inducing chirality with circularly polarized light. Science 2009, 323, 1435-1436. DOI: 10.1126/SCIENCE.1169338

47. The degree of CPL is given by the luminescence dissymmetry factor $g$ lum $(\lambda)=2\left(I_{\mathrm{L}}-I_{\mathrm{R}}\right) /\left(I_{\mathrm{L}}+I_{\mathrm{R}}\right)$, where $I_{\mathrm{L}}$ and $I_{\mathrm{R}}$ are the intensities of left and right circularly polarized emission, respectively.

48. Sanchez-Carnerero, E. M.; Moreno, F.; Maroto, B. L.; Agarrabeitia, A. R.; Banuelos, J.; Arbeloa, T.; Lopez-Arbeloa, I.; Ortiz, M. J.; Moya, S. d. 1., Unprecedented induced axial chirality in a molecular BODIPY dye: strongly bisignated electronic circular dichroism in the visible region. Chem. Commun. 2013, 49, 11641-11643. DOI: 10.1039/C3CC47570K. 
49. Bañuelos, J.; Lopez-Arbeloa, I.; García-Moreno, I.;Costela, A.; Infante, L.; Perez-Ojeda, E.; Palacios-Cuesta, M.; Ortiz, M. J. Controlling Optical Properties and Function of BODIPY by Using Asymmetric Substitution Effects. Chem. Eur. J. 2010, 16, 14094-14105. DOI: 10.1002/CHEM.201002095.

50. The degree of $\mathrm{CD}$ is given by the Kunh dissymmetry ratio, or absorption dissymmetry factor $g_{a b s}(\lambda)=2(\varepsilon \mathrm{L}-\varepsilon \mathrm{R}) /(\varepsilon \mathrm{L}+\varepsilon \mathrm{R})$, where $\varepsilon \mathrm{L}$ and $\varepsilon$ are the molar absorption coefficients for left and right circularly polarized light, respectively.

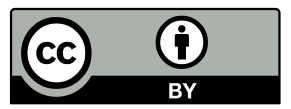

(C) 2017 by the authors. Submitted for possible open access publication under the terms and conditions of the Creative Commons Attribution (CC BY) license (http://creativecommons.org/licenses/by/4.0/). 